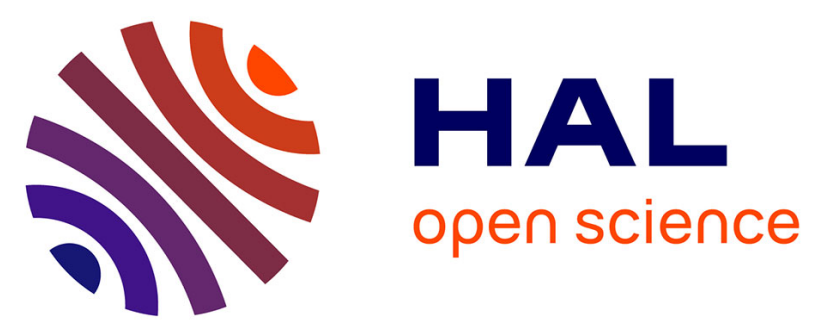

\title{
Modeling of isoamyl acetate production by fermentation with Pichia fermentans in an aerated system coupled to in situ extraction
}

\author{
Ana Karen Sánchez Castañeda, Violaine Athès, Marwen Moussa, Javier López \\ Miranda, Jesús Bernardo Páez Lerma, Ioan Cristian Trelea
}

\section{To cite this version:}

Ana Karen Sánchez Castañeda, Violaine Athès, Marwen Moussa, Javier López Miranda, Jesús Bernardo Páez Lerma, et al.. Modeling of isoamyl acetate production by fermentation with Pichia fermentans in an aerated system coupled to in situ extraction. Process Biochemistry, 2018, 65, pp.11-20. 10.1016/j.procbio.2017.10.010 . hal-01624572

\section{HAL Id: hal-01624572 \\ https://hal.science/hal-01624572}

Submitted on 26 Oct 2017

HAL is a multi-disciplinary open access archive for the deposit and dissemination of scientific research documents, whether they are published or not. The documents may come from teaching and research institutions in France or abroad, or from public or private research centers.
L'archive ouverte pluridisciplinaire HAL, est destinée au dépôt et à la diffusion de documents scientifiques de niveau recherche, publiés ou non, émanant des établissements d'enseignement et de recherche français ou étrangers, des laboratoires publics ou privés. 
Modeling of isoamyl acetate production by fermentation with Pichia fermentans

in an aerated system coupled to in situ extraction

Ana Karen Sánchez Castañeda ${ }^{\mathrm{a}, \mathrm{b}}$, Violaine Athès ${ }^{\mathrm{a}}$, Marwen Moussa ${ }^{\mathrm{a}}$, Javier López Miranda ${ }^{\mathrm{b}}$, Jesús Bernardo Páez Lerma ${ }^{\mathrm{b}}$, Nicolás Óscar Soto Cruz ; Ioan Cristian Trelea ${ }^{\mathrm{a}^{*}}$

${ }^{\mathrm{a} U M R} 782$ Génie et Microbiologie des Procédés Alimentaires (GMPA), AgroParisTech, INRA, Université Paris-Saclay, F-78850, Thiverval-Grignon

${ }^{\mathrm{b}}$ Tecnológico Nacional de México, Instituto Tecnológico de Durango, Departamento de Ingenierías Química-Bioquímicas. Blvd. Felipe Pescador 1830 Ote. Col Nueva Vizcaya. Durango, Dgo. 34080, México.

Authors e-mail: ana-karen.sanchez@inra.fr, violaine.athes-dutour@inra.fr, marwen.moussa@agroparistech.fr, jlopez@itdurango.edu.mx, jpaez@itdurango.edu.mx,nsoto@itdurango.edu.mx.

*Corresponding author:

Ioan Cristian Trelea

Tel: +331308154 90. Fax: +33130815597.

E-mail address: cristian.trelea@agroparistech.fr 


\section{Abstract}

This study deals with the production of isoamyl acetate (IAA) by fermentation of sugar cane molasses with the strain Pichia fermentans ITD00165, using L-leucine as precursor. A mathematical model that describes the experimental data from fermentation was developed for its use as a tool for further process optimization. The fermentation system was constantly aerated and coupled to liquid-liquid in situ extraction with decane as the recovery solvent. Thus, the model integrates the biological production of IAA, its partition coefficient in the two liquid phase system and the stripping effect of aeration. A productivity of $26-\mathrm{mg}-\mathrm{L}^{-1} \mathrm{~h}^{-1}$ was obtained with addition of $4-\mathrm{g}-\mathrm{L}^{-1}$ of L-leucine at $12-\mathrm{h}$ of fermentation. The use of the model for process optimization was explored. According to it, the maximum theoretical productivity that can be obtained is $63-\mathrm{mg}-\mathrm{L}^{-1} \mathrm{~h}^{-1}$. The model was used to determine that $1.6-\mathrm{g}-\mathrm{L}^{-1}$ is the minimum concentration of L-leucine that can be added without significantly reducing IAA production. Also, it makes possible to propose an adequate decane/culture medium ratio, to have a desired final concentration and amount of recovered IAA. This value can be adjusted based on the needs of further purification steps and is useful to define a global economic optimum of the process.

Keywords: Aroma production, fermentation kinetics, partition coefficient, simulation, natural flavoring substance.

Chemical compounds studied in this article 
Isoamyl acetate (PubChem CID: 31276); Decane (PubChem CID: 15600); L-leucine (PubChem CID: 6106). 


\section{Introduction}

2 Esters of short-chain fatty acids are important flavor and fragrance compounds

3 widely used in the food and beverage industries. Isoamyl acetate (IAA) is

4 characterized by its strong smell of banana which gives it a very important place in

5 food, pharmaceutical and perfumery industries with a demand of 75 tons per year in

6 USA alone in 2010 [1-3], increasing over the years. This substance is obtained by

7 chemical synthesis, extraction from natural sources, or fermentation [4].

8 In recent years, the interest towards the production of flavor compounds through

9 white biotechnology processes over traditional methods has increased. Principal

10 reasons are that chemical synthesis often consists in an environmentally unfriendly

11 production process, with important drawbacks such as poor reactions selectivity

12 resulting in racemic mixtures, low yields, and high downstream costs [5,6]. Also,

13 consumers have developed an apprehensive attitude towards these synthetic 14 compounds, especially if the products are related to food or domestic usage.

15 Moreover, the extraction of flavoring compounds from natural sources gives very low 16 yields and has potential difficulties with obtaining the raw material $[3,4,7]$. Contrary

17 to chemical synthesis, flavors obtained by fermentation can have the "natural

18 flavoring substance" classification by the European (EC No 1334/2008) and U.S.

19 (21CFR101.22) regulations, which allows using them safely as an additive in food

20 and beverages. This has been the main reason for developing biochemical processes

21 over the years, but presently, after years of research, the inherent advantages of white

22 biotechnology processes are the driving force for its application: operation under mild 
23 and more environmentally friendly conditions, as well as chemical and stereo

24 specificity of the obtained compounds, are the most important ones [8].

25 There are several published studies focused on IAA biological production. They 26 include enzymatic synthesis using lipases and esterases [1,3,9-15] and fermentation 27 process by microorganisms, especially yeasts strains [6,16-20]. Whole cell 28 fermentation can be a more economical method than enzymatic systems and easier to 29 scale up to industrial level. There are some encouraging studies with interesting IAA 30 productivities in the literature; for example, Yilmaztekin et al. [6] used a Williopsis 31 saturnus strain in a medium composed of beet molasses and fusel alcohols as a source 32 of isoamyl alcohol (IAOH), a precursor of the ester. A productivity of $2.46 \mathrm{mg} \mathrm{L}^{-1} \mathrm{~h}^{-1}$ 33 was obtained by adding 1\% of fusel alcohol at $72 \mathrm{~h}$. Quilter et al. [19], obtained 1.16 $34 \mathrm{mg} \mathrm{L}^{-1} \mathrm{~h}^{-1}$ using a mutant strain of Saccharomyces cerevisiae and testing several 35 fermentation conditions. However, these values are not high enough to make the 36 process attractive at industrial level and further optimization is needed.

37 In fermentative processes, the production of IAA is strongly affected by the medium 38 composition, fermentation conditions and the microorganism used $[6,18,19]$. 39 However, a very important factor to consider is physical behavior of IAA in 40 fermentation medium once produced. IAA is a very volatile compound and its 41 production presents some difficulties including phase separation and challenging 42 product recovery. Moreover, IAA production could be favored by chemical 43 equilibrium shift through in situ extraction. A way to improve the performance of 44 fermentative processes is the direct recovery of the desired product, also called In Situ 45 Product Recovery (ISPR). This technique can overcome the inhibition by product 
46 accumulation and also decreases the loss of cellular viability caused by product

47 toxicity [21,22]. Liquid-liquid extraction with organic solvents is a promising method 48 for IAA recovery, since IAA is more soluble in them than in aqueous solutions. For

49 the same reasons, lipase-catalyzed esterification is carried out in solvent systems $50 \quad[12,14,15,23]$.

51 Modeling and simulation has become the most used tool for processes optimization, 52 since it makes possible to explore a wider range of parameter values at a minimum 53 price, compared to experimental approach. Thus, the aim of this work is to develop a 54 model able to describe the production and extraction of IAA from sugar cane 55 molasses, with L-leucine added as precursor, by fermentation with the strain Pichia 56 fermentans ITD00165. The model includes the behavior of IAA in an aerated 57 fermentation system coupled to an in situ extraction with a solvent (decane). As the 58 aeration factor affects the retention of IAA in the system due to a stripping effect, the 59 model is useful as an optimization tool to find the conditions in which the highest 60 amount of IAA could be produced and recovered.

\section{Materials and methods}

\section{1.1. Fermentations}

\section{1.1.1. Yeast strain}

64 The strain Pichia fermentans ITD00165 was used. It was one of the strains isolated 65 from a spontaneous fermentation of Agave duranguensis obtained from the Microbial 66 Biotechnology Lab's Culture Collection at the Durango Institute of Technology. It 67 was chosen because of its high IAA production capacity [24]. 


\subsubsection{Isoamyl acetate production}

69 Fermentations were carried out in $1 \mathrm{~L}$ glass containers with a diameter/height ratio of

$701: 2$, where $600 \mathrm{~mL}$ of culture medium were inoculated with an initial concentration of

$711 \times 10^{7}$ cells $\mathrm{mL}^{-1}$ of a $24 \mathrm{~h}$ pre-grown culture. The pre-culture was inoculated in 100 $72 \mathrm{~mL}$ of the sugar cane molasses medium in $250 \mathrm{~mL}$ Erlenmeyer flasks, with agitation 73 of $120 \mathrm{rpm}$ at $28^{\circ} \mathrm{C}$. In order to retain the IAA produced, $150 \mathrm{~mL}$ of decane (Sigma74 Aldrich, USA) was put at the top of the culture medium, creating an in situ 75 entrapping system. Compressed air was fed into the medium with a flow rate of 600 $76 \mathrm{~mL} \mathrm{~min}^{-1}(1 \mathrm{VVM})$ at the bottom of the vessel, in order to provide oxygen to the cells 77 and to agitate the culture medium. No other agitation system was used, thus liquid 78 phases were not mixed, only a slight local dispersion at liquid/liquid interface was 79 observed. The temperature was maintained at $28{ }^{\circ} \mathrm{C}$ and the fermentation was 80 monitored during $24 \mathrm{~h}$. In fermentations, the effect of addition of the amino acid L81 leucine (Sigma-Aldrich, USA) as a precursor of IAA was tested. Therefore, three 82 experiments were carried out: 1) Fermentation with no addition of L-leucine, 2) The 83 addition of $4 \mathrm{~g} \mathrm{~L}^{-1}$ of L-leucine at the beginning of fermentation $\left(\mathrm{t}_{0}\right)$ and 3 ) adding $4 \mathrm{~g}$ $84 \mathrm{~L}^{-1}$ after $12 \mathrm{~h}$ of fermentation $\left(\mathrm{t}_{12}\right)$. All experiments were performed in duplicate.

\subsubsection{Process monitoring}

86 Samples of $1 \mathrm{~mL}$ of medium and decane phases were taken for 24 hours, every 4 87 hours for experiments 1 and 3, and every 2 hours for experiment 2. Monitoring 88 consisted in measurements of biomass by staining viable count with methylene blue 89 in a Neubauer chamber and dry weight; reducing sugars by DNS technique [25]; L90 leucine and the nitrogen $(\mathrm{N})$ source in molasses by a colorimetric method with 
91 ninhydrin [26]; and IAA production measured in the decane phase by gas 92 chromatography on a Gas Chromatograph 6890N (Agilent Technologies, USA) 93 equipped with a flame ionization detector (FID) and a HP-Innowax column (Hewlett-

94 Packard, USA) (length, $30 \mathrm{~m}$; inside diameter, $0.25 \mathrm{~mm}$; film thickness, $0.25 \mu \mathrm{m}$ ).

95 Temperatures were as used by Rojas et al.[20] with some modifications: injector 96 block and detector 220 and $300{ }^{\circ} \mathrm{C}$, respectively. The oven temperature was 97 programmed as follows: equilibrated at $60^{\circ} \mathrm{C}$ for $10 \mathrm{~min}$, followed by a ramp of $20^{\circ} \mathrm{C}$ $98 \mathrm{~min}^{-1}$, up to $250^{\circ} \mathrm{C}$. Ethanol and $\mathrm{IAOH}$ were analyzed in culture medium by gas 99 chromatography with a method designed for alcohols [27]: injector block and 100 detector 250 and $300^{\circ} \mathrm{C}$, respectively; 1:10 split ratio; oven temperature equilibrated 101 at $40^{\circ} \mathrm{C}$ for $5 \mathrm{~min}$, followed by a ramp of $10^{\circ} \mathrm{C} \min ^{-1}$, up to $260^{\circ} \mathrm{C}$.

\section{1.2. Aeration effect on retention of isoamyl acetate in decane}

103 Experiments were carried out in the same conditions as fermentations but without cell

104 inoculation. Instead, IAA was added to the system at a concentration of $1 \mathrm{~g} \mathrm{~L}^{-1}$ in two 105 different conditions: 1) Adding IAA into the culture medium and 2) the same amount 106 of IAA was added into the decane phase. Samples of decane were taken periodically 107 and were analyzed by gas chromatography as mentioned before. All experiments 108 were performed in duplicate.

109 1.3. Molasses medium analysis by HPLC

110 A sample of fermentation medium, consisting in molasses diluted at $100 \mathrm{~g} \mathrm{~L}^{-1}$ with 111 distilled water was analyzed by HPLC in order to determine the sugars and 112 aminoacids content. Sugars were analyzed using a column Biorad Aminex with a 
113 stationary phase of sulfonated divinyl benzene-styrene (HPX-87H, $300 \mathrm{~mm} \times 7.8 \mathrm{~mm}$

$114 \times 9 \mu \mathrm{m}$ ), at a temperature of $35^{\circ} \mathrm{C}$, UV detection was made at $210 \mathrm{~nm}$. For

115 aminoacids, anAccQ-Fluor Reagent Kit was injected in a Waters column (ACCQ-

$116 \mathrm{TAG}, 150 \mathrm{~mm} \times 3.9 \times 4 \mu \mathrm{m})$, at a temperature of $34^{\circ} \mathrm{C}$, and fluorescent $\mathrm{UV}$ detection

117 was made at $250 \mathrm{~nm}$ for excitation and $395 \mathrm{~nm}$ for emission.

118 1.4. Determination of partition coefficients

119 1.4.1. Gas-liquid partition coefficient $\left(K_{g q}\right)$

120 The Phase Ratio Variation (PRV) method was used as described by Morakul et al.,

121 [28]. In order to evaluate the effect of the changes in medium composition during

122 fermentation, 8 different solutions of IAA at $1 \mathrm{~g} \mathrm{~L}^{-1}$ were prepared in different

123 aqueous matrices, simulating different stages of fermentation during IAA production:

124 1) water, 2) sucrose $100 \mathrm{~g} \mathrm{~L}^{-1}$, 3) ethanol $10 \mathrm{~g} \mathrm{~L}^{-1}$, 4) sucrose $150 \mathrm{~g} \mathrm{~L}^{-1}$, 5) ethanol 15

$\left.125 \mathrm{~g} \mathrm{~L}^{-1}, 6\right)$ sucrose $50 \mathrm{~g} \mathrm{~L}^{-1}+$ ethanol $\left.5 \mathrm{~g} \mathrm{~L}^{-1}, 7\right)$ sucrose $25 \mathrm{~g} \mathrm{~L}^{-1}+$ ethanol $7.5 \mathrm{~g} \mathrm{~L}^{-1}$, and

126 8) sugar cane molasses $100 \mathrm{~g} \mathrm{~L}^{-1}$. These conditions were proposed considering a 127 maximum production of ethanol of $15 \mathrm{~g} \mathrm{~L}^{-1}$ and a maximum sugar concentration of

$128100 \mathrm{~g} \mathrm{~L}^{-1}$ in the fermentation medium during the process. Aliquots of $50 \mu \mathrm{L}$ to $2 \mathrm{~mL}$ 129 from each solution were introduced into four different headspace vials $(22 \mathrm{~mL}$,

130 Chromacol, France) closed with Teflon/silicone septa in metallic caps, giving volume 131 ratios between gas and liquid phases $(\beta)$ of 10 to 439 . The vials were then 132 equilibrated at $28^{\circ} \mathrm{C}$ for at least $1 \mathrm{~h}$ (the time required to reach equilibrium in static 133 conditions). Once equilibrium was reached, a $500 \mu \mathrm{L}$ sample of headspace gas was 134 taken with a gastight syringe, preheated to $40{ }^{\circ} \mathrm{C}$, in an automatic headspace sampler 135 CTC Pal and injected with a $100 \mu \mathrm{L} \mathrm{s}^{-1}$ rate to a gas chromatograph (Agilent 
136 G1530A, Germany) using FID detector. A HP-INNOWax column $(30 \mathrm{~m} \times 0.53 \mathrm{~mm}$

$137 \times 1.00 \mu \mathrm{m})$ from Agilent (stationary phase: polyethylene glycol) was used, using

138 helium as a carrier gas with a flow rate of $10 \mathrm{~mL} \mathrm{~min}^{-1}$. The oven temperature started 139 at $60{ }^{\circ} \mathrm{C}$ followed by a ramp of $10{ }^{\circ} \mathrm{C} \mathrm{min}^{-1}$ up to $220^{\circ} \mathrm{C}$. Injector and FID detector 140 temperature was $250^{\circ} \mathrm{C}$. Peaks areas were acquired with Agilent GC Chemstation 141 software. A mass balance equation was used for partition coefficients calculation, as 142 described by Ettre et al. [29].The gas-liquid partition coefficient for IAA was 143 expressed as the concentration ratio $\left(K_{g q}\right)$ :

$$
K_{g q}=\frac{C_{g}^{*}}{C_{q}^{*}}
$$

144 with $C_{g}^{*}$ and $C_{q}^{*}$ being IAA concentration at equilibrium in the gas and aqueous 145 phases respectively.

\section{$146 \quad$ 1.4.2. Liquid-liquid partition coefficient $\left(K_{d q}\right)$}

147 In this determination, different IAA solutions of $0.1 \mathrm{~g} \mathrm{~L}^{-1}$ in aqueous phase were also 148 prepared changing the matrix composition in order to simulate the changes in the 149 medium during fermentation. The solutions were 1) water, 2) sucrose $100 \mathrm{~g} \mathrm{~L}^{-1}, 3$ ) 150 ethanol $\left.10 \mathrm{~g} \mathrm{~L}^{-1}, 4\right)$ sucrose $25 \mathrm{~g} \mathrm{~L}^{-1}+$ ethanol $\left.7.5 \mathrm{~g} \mathrm{~L}^{-1}, 5\right)$ sucrose $50 \mathrm{~g} \mathrm{~L}^{-1}+$ ethanol

$\left.1515 \mathrm{~g} \mathrm{~L}^{-1}, 6\right)$ sucrose $70 \mathrm{~g} \mathrm{~L}^{-1}+$ ethanol $10 \mathrm{~g} \mathrm{~L}^{-1}$, and 7) sugar cane molasses $100 \mathrm{~g} \mathrm{~L}^{-1}$. 152 Some solutions had different sucrose and ethanol concentrations from those used in 153 the gas-liquid partition coefficient measurements $\left(K_{g q}\right)$, in order to have intermediate 154 concentration values. Then, $25 \mathrm{~mL}$ of each solution were put in contact with $25 \mathrm{~mL}$ 155 of decane in $60 \mathrm{~mL}$ separation funnels. They were left to reach the equilibrium in 156 static conditions for at least $48 \mathrm{~h}$ at a temperature of $28^{\circ} \mathrm{C}$. 
157 After equilibrium was reached, $1.5 \mathrm{~mL}$ samples of aqueous and decane phase were 158 taken in $2 \mathrm{~mL}$ vials closed with Teflon/silicone septa in metallic caps and stored in 159 the tray at $4^{\circ} \mathrm{C}$. A sample of $1 \mu \mathrm{L}$ was taken from each vial with a water-tight syringe, 160 in an automatic headspace sampler CTC Pal and injected with a $5 \mu \mathrm{L} \mathrm{s}^{-1}$ rate to the 161 gas chromatograph (G 1530A, Germany), equipped with the same column. For the

162 analysis method, oven temperature started at $35^{\circ} \mathrm{C}$ followed by a ramp of $5^{\circ} \mathrm{C} \min ^{-1}$ 163 to $60{ }^{\circ} \mathrm{C}$ and another one of $15^{\circ} \mathrm{C} \min ^{-1}$ up to $220{ }^{\circ} \mathrm{C}$. Injector and FID detector 164 temperature was set to $250^{\circ} \mathrm{C}$.

165 IAA concentrations in both phases were determined using adequate calibration 166 curves. Partition coefficient $K_{d q}$ was calculated as the ratio at equilibrium of IAA in 167 decane $C_{d}^{*}$ and in aqueous solution $C_{q}^{*}$ :

$$
K_{d q}=\frac{C_{d}^{*}}{C_{q}^{*}}
$$

168 1.4.3. Statistical analysis

169 Partition coefficient values were compared with a One Way Analysis of Variance

170 (ANOVA) and the Fisher Least Significant Difference (LSD) post-hoc test with the 171 program Statistica version 7.0 (StatSoft, USA).

172 1.5. Dynamic model

173 The equations of the mathematical model were implemented in a program written 174 under Matlab 2013b (The Matworks Inc, Natick, MA). The parameters were 175 identified by linear and nonlinear regression, using the Statistic Toolbox. 
177 The values of gas-liquid and liquid-liquid partition coefficients were fitted to a

178 statistical model that accounts for dependence on the medium composition (at 179 constant temperature), as described by Mouret et al. [30]. Sugar and ethanol 180 concentrations, their interaction and the effect of molasses were considered:

$$
\begin{gathered}
\log K_{d q}=p_{a}+p_{b} S_{t}+p_{c} E+p_{d} S_{t} E+p_{e} M \\
\log K_{g q}=p_{1}+p_{2} S_{t}+p_{3} E+p_{4} S_{t} E+p_{5} M
\end{gathered}
$$

181 where $K_{g q}$ and $K_{d q}$ are the gas-liquid and liquid-liquid partition coefficients 182 respectively, $E$ is the ethanol concentration $\left(\mathrm{g} \mathrm{L}^{-1}\right), S_{t}$ is the sugar concentration $\left(\mathrm{g} \mathrm{L}^{-}\right.$

$183^{1}$ ), and $M$ is the presence of molasses ( 0 or 1$)$ in aqueous phase. Model parameters $184 p_{1} \ldots p_{5}$ and $p_{a} \ldots p_{e}$ are constants depending on the considered compound and 185 temperature, in this case IAA at $28^{\circ} \mathrm{C}$. Parameter values were determined by stepwise 186 descending linear regression, starting with the complete model and removing 187 statistically not significant terms one by one, starting with the ones with the largest 188 coefficient of variation.

189 1.5.2. Modeling the isoamyl acetate loss in gas phase by stripping

190 IAA transfer in the system was considered as follows: it is transferred from the 191 aqueous medium $(q)$, where it is synthesized by the cells, simultaneously to 1) the 192 decane phase $(d)$; and 2) to the gas phase $(g)$. Also, a fraction of the IAA in decane 193 phase is transferred to the gas phase. Medium and decane phases are very little 194 dispersed into each other, so the transfer to the gas phase is different in each liquid 195 phase. The IAA transferred to the air fed in the fermentation system was considered 196 as lost due to a stripping effect. Therefore, this could be described by the model 
197 developed by Marin et al.[31] with some modifications (Equation 5), considering

198 IAA present in both decane and fermentation medium, and the removal by the air

199 flow passing through the system. The global mass balance between the liquids,

200 namely decane $(d)$ + aqueous medium $(q)$ and the stripping gas $(g)$ was written as:

$$
\frac{d\left(C_{d} V_{d}+C_{q} V_{q}\right)}{d t}=-C_{g} \cdot Q_{g}
$$

201 where $C_{d}, C_{q}$ and $C_{g}$ are IAA concentration in decane, aqueous and gas phase 202 respectively, $V_{d}$ and $V_{q}$ are the volumes $(\mathrm{mL})$ of decane and aqueous phase 203 respectively, and $Q_{g}$ is the air flow rate through the system $\left(\mathrm{mL} \mathrm{h}^{-1}\right)$. It was assumed 204 that the liquid and gas phases were not in equilibrium, and the expression of mass 205 transfer from the two liquid phases $(d, q)$ to the air flow (gas phase, $g$ ) is:

$$
C_{g} \cdot Q_{g}=k_{q} A_{q}\left(C_{q}-\frac{C_{g}}{K_{g q}}\right)+k_{d} A_{d}\left(C_{d}-\frac{C_{g}}{K_{g d}}\right)
$$

206 Here $k_{q}$ and $k_{d}$ are the overall mass transfer coefficients of IAA between the gas and 207 the aqueous and decane phases respectively, and $A_{q}$ and $A_{d}$ are the interfacial areas 208 of each phase with air bubbles [31]. $K_{g d}$ is the partition coefficient between the gas 209 and decane phases determined from Equations 1 and 2 according to Equation 7.

$$
K_{g d} \stackrel{\text { def }}{=} \frac{C_{g}^{*}}{C_{d}^{*}}=\frac{K_{g q}}{K_{d q}}
$$

210 At time scale of IAA production process by fermentation (12 $\mathrm{h})$, equilibrium was 211 considered between the aqueous phase and decane: 


$$
C_{q}=\frac{C_{d}}{K_{d q}}
$$

212 After substituting $C_{q}$ from Equation 8, equation 6 was solved for $C_{g}$, giving:

$$
C_{g}=\frac{k_{l} a_{l}}{\left(D_{g}+\frac{k_{l} a_{l}}{K_{g d}}\right)} \cdot C_{d}
$$

213 where

$$
k_{l} a_{l}=\frac{\left(\frac{k_{q} A_{q}}{K_{d q}}+k_{d} A_{d}\right)}{V_{q}} \quad \text { and } \quad D_{g}=\frac{Q_{g}}{V_{q}}
$$

214 The product $k_{l} a_{l}$ is a volumetric mass transfer coefficient which characterizes

215 transfer between the liquid phase (decane + aqueous medium) as a whole and the gas 216 phase and $D_{g}$ is the specific aeration rate of the medium.

217 Substituting Equation 9 in 5, the loss rate of IAA, considering decane as the reference 218 medium, is obtained:

$$
\frac{d C_{d}}{d t}=-\frac{k_{l} a_{l} \cdot D_{g}}{\left(D_{g}+\frac{k_{l} a_{l}}{K_{g d}}\right)\left(\frac{V_{d}}{V_{q}}+\frac{1}{K_{d q}}\right)} \cdot C_{d}
$$

219 Equation (11) can be solved easily assuming $K_{i}, k_{i}, A_{i}$ and $V_{i}$ to be constant in 220 isothermal conditions, leading to Equation 12 that gives the residual concentration of 221 IAA in decane considering the stripping effect of the air fed into the system: 


$$
C_{d}=C_{d 0} \exp \left(-\frac{k_{l} a_{l} \cdot D_{g}}{\left(D_{g}+\frac{k_{l} a_{l}}{K_{g d}}\right)\left(\frac{V_{d}}{V_{q}}+\frac{1}{K_{d q}}\right)} t\right)
$$

223 The only unknown parameter in this equation is the volumetric mass transfer

224 coefficient $\left(k_{l} a_{l}\right)$. In order to verify the assumption that liquid phases are not in 225 equilibrium with the gas phase and IAA stripping is limited by mass transfer, a 226 variant of the model considering equilibrium between the gas and the liquid phases 227 was also considered for comparison, corresponding to a very large $k_{l} a_{l}$ value. In that 228 situation, Equation 12 reduces to Equation 13:

$$
C_{d}=C_{d 0} \exp \left[-K_{g d} \cdot \frac{D_{g}}{\left(\frac{V_{d}}{V_{q}}+\frac{1}{K_{d q}}\right)} t\right]
$$

\section{1.6. Modeling the isoamyl acetate production by fermentation}

230 To develop the fermentation model, the metabolic pathway involved in IAA synthesis

231 by yeast was considered (Figure 1) [32]. IAA is formed from esterification of IAOH 232 and the acetyl group from acetyl coenzyme A. Depending on medium composition, 233 IAOH could be produced de novo from sugars consumption or by a catabolic 234 pathway from degradation of the aminoacid L-leucine, called Ehrlich pathway [33]. 235 The acetyl-CoA formed during metabolism comes mainly from sugar consumption 236 and is used in several other reactions like biosynthesis of lipids, amino acids, fatty 237 acids, and is also involved in the tricarboxylic acids cycle [32]. 
238 Table 1 shows the equations used to describe the production and consumption of the

239 compounds considered in the fermentation model, without considering extraction by

240 decane and losses by stripping. Biomass, ethanol, IAOH and IAA are the produced

241 compounds, while fermentable reducing sugar, L-leucine and IAOH as well, are the

242 consumed ones. To describe biomass production, the Monod equation was used

243 (Equations 14 and 20). In that case biomass production is proportional to fermentable

244 sugars consumption. Therefore, fermentable sugars consumption was described by

245 Equation 18, $Y_{X / S}$ being the yield of biomass production related to sugar

246 consumption. Ethanol production was also considered to be proportional to sugar

247 consumption (Equation 15), using the corresponding yield $\left(Y_{E t O H / S}\right)$.

248 According to the metabolic pathway (Figure 1), IAOH is formed from both sugars

249 and L-leucine consumption, with the corresponding specifics production rates $\xi_{S}$ and

$250 \xi_{L}$ and is consumed for IAA synthesis with yield $Y_{I A A / I A O H}$ (Equation 16). For IAA

251 production from $\mathrm{IAOH}$, an analogous of the Monod equation was used, considering

252 both fermentable sugars and IAOH as limiting substrates (Equations 17 and 23). L-

253 leucine consumption is described by Equation 19, the specific consumption rate also

254 involving fermentable sugar as limiting substrate (Equation 22).

255 1.6.1. Coupled model

256 In order to represent the IAA retained in the fermentation system with decane and

257 stripping, the mass balance equation for IAA production from the fermentation model

258 (Equation 17) was modified to include IAA partition between the fermentation 
259 medium and decane as well as IAA losses by stripping (Equation 11) leading to 260 equation 24:

$$
\frac{d C_{d}}{d t}=v X \frac{V_{q}}{V_{d}+\frac{V_{q}}{K_{d q}}}-\frac{k_{l} a_{l} \cdot D_{g}}{\left(D_{g}+\frac{k_{l} a_{l}}{K_{g d}}\right)\left(\frac{V_{d}}{V_{q}}+\frac{1}{K_{d q}}\right)} C_{d}
$$

261 The result was expressed in terms of IAA concentration in decane (assuming 262 equilibrium between fermentation medium and decane, Equation 8) because all 263 concentration measurements were performed in this phase. 


\section{Results and discussion}

\section{1.7. Model development}

266 1.7.1. Gas-liquid $\left(K_{g q}\right)$ and liquid-liquid $\left(K_{d q}\right)$ partition coefficients

267 Figure 2 shows the $K_{g q}$ values at different concentrations of ethanol and sucrose,

268 compounds that were chosen to simulate the medium composition during

269 fermentation. It can be observed that an increment on ethanol concentration increased

270 the solubility of the esters in the aqueous phase, decreasing their volatility. On the

271 other side, sugar concentration has a 'salting out' effect, increasing the volatility of

272 aroma compound. Thus, $K_{g q}$ value tends to decrease during fermentation. The same

273 tendencies were observed in the work of Morakul et al. [28].

274 Figure 3 shows liquid-liquid partition coefficient $\left(K_{d q}\right)$ values. As it can be observed,

275 changes in medium composition have a much stronger impact than on $K_{g q}$. Sugar

276 concentration has a higher "salting out" effect than on $K_{g q}$. In the case of molasses

277 solution, the $K_{d q}$ value is significantly smaller than for model solutions. This could

278 be because in molasses other components such as lipids, amino acids or minerals are

279 present, which could affect more importantly the $K_{d q}$ value.

280 Table 2 shows the parameter values obtained from the stepwise linear regression of $281 K_{g q}$ and $K_{d q}$ with the different simulated medium compositions. Parameters that are 282 not significantly different from zero were iteratively removed from the model, 283 beginning with the factor with the highest coefficient of variation [30]. For $K_{d q}$ 284 regression, ethanol and molasses had a significant effect. Sugar concentration 285 coefficient resulted not significant. Note that solutions prepared to represent 
286 fermentation conditions were a mixture of ethanol and sugar, inversely correlated as 287 in a real fermentation medium, which makes it difficult to differentiate each effect. 288 Thus, the absence of sugar coefficient in Equation 3 does not necessarily mean that 289 there is no effect. In the $K_{d q}$ equation, sugar effect could have been absorbed by the 290 ethanol coefficient. For example, in the work of Morakul et al. [34] the partition 291 coefficient equation is expressed only in terms of ethanol concentration but it 292 represents also sugar concentration in the medium, since they are inversely related in 293 fermentation conditions.

294 As it was expected, the concentration of molasses had an important effect in $K_{d q}$ 295 model, but is negligible in $K_{g q}$ model. These results show that complex medium 296 (molasses) composition has a stronger effect on $K_{d q}$ than on $K_{g q}$. Identifying which 297 compounds of the molasses solution have significant effects on $K_{d q}$ requires further 298 investigations.

\section{1.7.2. Isoamyl acetate loss by air stripping}

300 Figure 4 displays the experimental data obtained in stripping experiments after 301 adding IAA in aqueous and decane phase, together with model predictions.

302 Determination coefficient $\left(\mathrm{R}^{2}\right)$ values for both experiments were 0.913 and 0.996 303 respectively. In fermentation conditions, $2.5 \%$ of IAA per hour is lost due to aeration, 304 and the value of $k_{l} a_{l}$ coefficient that represents mass transfer from liquid to gas phase 305 was $0.0117 \pm 0.0003 \mathrm{~h}^{-1}$ (fitted using Equation 12). The relatively low value of the 306 volumetric mass transfer coefficient $k_{l} a_{l}$ for isoamyl acetate corresponds to reduced 307 IAA losses by stripping from the considered device, a desired feature in this case. 
308 Although aeration has an important effect on IAA loss from fermentation system,

309 Rojas et al. [20] observed that its production by non-Saccharomyces strains is

310 improved in highly aerobic culture conditions (shaking at $120 \mathrm{rpm}$ ), compared with

311 minimally aerobic conditions (without shaking). From all the strain tested, Pichia

312 anomala had the best IAA production and it had a 21 fold increase in aerobic

313 conditions. Also, Inoue et al. [35] reported a large amount of IAA produced by a

314 Hansenula mrakii strain in aerobic conditions.

315 For modeling purposes, it was assumed that decane and aqueous phase were in

316 equilibrium at the fermentation time scale. This assumption appears to be verified by

317 the experimental data shown in Figure 4. The experiment of IAA added into the

318 culture medium shows that after $1 \mathrm{~h}$ of aeration, IAA transferred into decane phase,

319 and in the following measurements a decrease of concentration due to aeration can be

320 observed. Thus, it appeared that within $1 \mathrm{~h}$, equilibrium between the two phases was

321 reached.

322 Figure 4 also shows in dashed lines the calculated loss of IAA with the assumption

323 that liquid and gaseous phases are in equilibrium (Equation 13). IAA losses are

324 clearly overestimated, meaning that the equilibrium between gas and liquid phases is

325 far from being reached, probably because the residence time of the air bubbles fed in

326 the system is very short. This corroborates the assumption that the stripping

327 phenomenon due to air feed is limited by mass transfer between liquid and gas phase,

328 and validates the model built on that basis.

329 1.7.3. Parameter estimation for the fermentation model 
330 Data obtained from fermentation experiments 1 (no addition of L-leucine) and 2

331 (addition of L-leucine at $\mathrm{t}_{0}$ ) were used to calculate the fermentation model parameters

332 (Table 3), while experiment 3 was used for validation of the model. Initial conditions

333 were taken from experimental values. In case of L-leucine in experiments 1 and 3 , the 334 initial value was obtained from HPLC analysis of molasses, showing that there was a

335 small amount of this aminoacid $\left(0.01 \mathrm{~g} \mathrm{~L}^{-1}\right)$. However, this amount is too small to 336 explain the IAA production with no addition of L-leucine into the medium, meaning 337 that there must be a pathway from sugar consumption to IAA synthesis as described 338 by Piendl and Geiger [32] and considered in the model.

339 The maximum specific growth rate $\mu_{\max }$ was calculated by linear regression of the 340 logarithm of biomass produced $(\log X)$ versus time $(t)$ values in the exponential 341 growth phase of fermentation. The value obtained $\left(\mu_{\max }=0.230 \pm 0.006 \mathrm{~h}^{-1}\right)$ is 342 somewhat lower than the ones found in other works dealing with yeast growth in 343 sugar cane molasses, where $\mu_{\max }$ can vary from $0.24-0.45 \mathrm{~h}^{-1}$ due to the difference in 344 nutrient or inhibitor composition in molasses, ambient conditions and the yeast strain 345 used [36-38]. Yields values $Y_{X / S}$ and $Y_{E t O H / S}$ were calculated by linear regression of 346 biomass and ethanol concentrations respectively vs. reducing sugars concentration. 347 For $Y_{I A A / I A O H}$ value, the stoechiometric value 130/88 was considered (ratio of IAA 348 and IAOH molecular weights). Values of $\xi_{\text {Smax }}, \xi_{\text {Lmax }}, v_{\max }, K_{S}$ and $Y_{I A O H / L}$ were 349 determined by fitting the model simultaneously to biomass, sugar, L-Leucine, IAOH 350 concentration measurements in the fermentation medium and IAA concentration 351 measurements in decane. 
352 In the case of $K_{S I A}, K_{L}$ and $K_{I A O H}$ values, it was found that in a range from 0 to $0.05 \mathrm{~g}$

$353 \mathrm{~L}^{-1}$ their value had a minor effect on the model predictions. It was not possible to

354 determine exact values for these parameters with the experimental data available,

355 because experiments were performed in batch mode and corresponding substrates

356 (sugar, L-leucine, IAOH) were rate limiting during too short time periods. These

357 parameters were thus fixed to $0.02 \mathrm{~g} \mathrm{~L}^{-1}$. For $K_{S}$, a value of $6.41 \pm 0.57 \mathrm{~g} \mathrm{~L}^{-1}$ was

358 found. This value depends on numerous factors such as environmental conditions,

359 composition of the medium and the strain used, so the range of values found in the

360 literature is quite extensive. For example Das et al. [38] determined a $K_{S}$ of $1.53 \mathrm{~g} \mathrm{~L}^{-1}$

361 in fermentation with Pichia fermentans in sugar cane bagasse extract, Ponce et al.

362 [37] determined a value of $4.1 \mathrm{~g} \mathrm{~L}^{-1}$ for Saccharomyces cerevisiae in fermentation of

363 sugar cane molasses. However, the value obtained in the present study is higher than

364 the works mentioned before, which confirms that substrate limitation coefficients

365 cannot be reliably determined in batch fermentations. Other micronutrients might

366 become limiting before complete sugar exhaustion.

\section{1.8. Model validation}

368 Once all model parameters were determined, data obtained from Experiment 3

369 (addition of L-leucine at $\mathrm{t}_{12}$ ) was used for model validation. Figure 5 shows the model

370 predictions compared to experimental data. In general, it was obtained a good

371 agreement for all considered compounds. Sugar consumption was quite well

372 described by the model $\left(\mathrm{R}^{2}=0.986\right)$. The amount of the fermentable sugars was taken

373 as a fixed fraction of the total sugar concentration present in molasses, determined as

$37435 \%$ in Experiments 1 and 2. Biomass and ethanol are produced proportionally to the 
375 sugar consumption, in agreement with the modeling assumptions; ethanol production 376 was well described by the model $\left(\mathrm{R}^{2}=0.977\right)$. However, biomass is slightly 377 underestimated by about $13 \%\left(\mathrm{R}^{2}=0.917\right)$, which means that the growth rate $\mu_{\max }$ 378 and yield $Y_{X / S}$ values were slightly higher in Experiment 3 than in Experiments 1 and 3792.

380 Figure 5 shows that before $12 \mathrm{~h}$ of fermentation, IAOH was produced from sugars at 381 a low specific rate $\xi_{\mathrm{S}}$, and almost entirely converted to IAA. After L-leucine addition, 382 the production rate of IAOH increased significantly since the Ehrlich pathway 383 participated to the synthesis with a higher specific rate $\xi_{L}$. This is consistent with 384 parameter values reported in Table 3, where $\xi_{\text {Lmax }}>\xi_{\text {Smax }}$. Most of IAOH produced 385 was converted to IAA at a specific rate $v$, which is consistent with $v_{\max }>\xi_{\text {Lmax }}$ in 386 Table 3. However, it can be observed that there is a fraction of IAOH accumulated in 387 the fermentation medium, also described by the model $\left(\mathrm{R}^{2}=0.819\right)$.

388 IAOH accumulation is an important point to pay attention, since it has been proved 389 that this compound has an inhibitory effect on yeast cells growth. Saccharomyces 390 cerevisiae growth is slower at a concentration of about $4 \mathrm{~g} \mathrm{~L}^{-1}[39,40]$; and Williopsis 391 saturnus growth is inhibited at concentrations of fusel oil greater than $2 \%$ (about $8 \mathrm{~g}$ $392 \mathrm{~L}^{-1}$ of $\left.\mathrm{IAOH}\right)$. In this study, IAOH concentration determined in all the experiments 393 was less than $0.74 \mathrm{~g} \mathrm{~L}^{-1}$, a small value compared to those found in the literature. This 394 is an advantage of maintaining a low IAA concentration in fermentation medium by 395 ISPR, which accelerates IAOH esterification, reducing its accumulation. 
396 The accumulation of IAA was quite well described by the model $\left(\mathrm{R}^{2}=0.952\right)$ which

397 also calculated its actual production without losses by stripping (Figure 5). Model

398 calculations indicate an amount of about $17 \%$ of IAA lost by stripping in these

399 fermentation conditions. The highest IAA productivity obtained in experimental

400 conditions was $26 \mathrm{mg} \mathrm{L}^{-1} \mathrm{~h}^{-1}$ with addition of $4 \mathrm{~g} \mathrm{~L}^{-1}$ of L-leucine at $12 \mathrm{~h}$ of

401 fermentation, which is higher than other values reported in the literature obtained by

402 yeast fermentation without in situ extraction [6,41].

403 1.9. Improvement strategies for isoamyl acetate production and retention

404 The developed model can be used as a tool to simulate the process of IAA production 405 in different conditions in order to find those that results in a better IAA production 406 and retention, with a more efficient use of L-leucine and decane. Key conditions that 407 can be modified in order to improve production and retention in the system are: i) the 408 time and amount of L-leucine addition, and ii) the decane to culture medium volume 409 ratio in fermentation system.

410 L-leucine was added to the medium at a concentration of $4 \mathrm{~g} \mathrm{~L}^{-1}$, however, 411 experimental data shows that it was not completely consumed by the cells, either 412 added from the beginning of fermentation or after $12 \mathrm{~h}$. The model was used to test 413 different initial concentrations of L-leucine and simulate resulting IAA concentration 414 in decane. It was found that at concentrations of $1.6 \mathrm{~g} \mathrm{~L}^{-1}$ of L-leucine or higher, the 415 IAA final concentration is not significantly different from IAA production with $4 \mathrm{~g} \mathrm{~L}^{-}$ $416{ }^{1}$ of L-leucine, as shown in Figure 6. 
417 Figure 7 a shows IAA distribution in the fermentation-extraction system at different 418 decane/medium ratios. It can be observed that the amount of IAA recovered in decane 419 phase increases by increasing the decane volume, as one may expect. A better 420 extraction percentage from the fermentation medium and lower losses by air stripping 421 are obtained. Although the amount of product retained increases with the amount of 422 decane used, final concentration of IAA tends to decrease as shown in Figure 7b, 423 which means obtaining an increasingly diluted solution and higher costs of 424 subsequent product purification. The model is thus a useful decision making tool to 425 determine the appropriate amount of decane, taking into account losses, the retained 426 IAA fraction and the type of downstream process to be used for purification. In order 427 to have an idea of the maximum potential production of the process, a simulation was 428 performed with a very high decane to culture medium ratio (100:1), assuming that 429 there will be no significant IAA loss in this condition. According to the model, with $4301.6 \mathrm{~g} \mathrm{~L}^{-1}$ of L-leucine one can obtain a maximum theoretical productivity of $63 \mathrm{mg} \mathrm{L}$ $431{ }^{1} \mathrm{~h}^{-1}$, based on IAA recovered in decane data. The actual value of solvent/medium 432 ratio has to be selected considering the need for further purification steps. The model 433 is thus a useful tool to perform an economic evaluation of the process, in order to 434 optimize costs. 


\section{Conclusion}

436 A model able to describe isoamyl acetate (IAA) production from sugar cane molasses

437 and L-leucine as precursor, by the strain Pichia fermentans ITD00165 was developed

438 and successfully used to predict the ester production indifferent conditions. It

439 reproduces quite well the coupled phenomena of the in situ production/extraction

440 process, and allows identifying the key points that can be improved to increase

441 production. The in situ extraction with decane resulted in several advantages: it

442 increased IAA production by decreasing product inhibition and IAOH accumulation

443 in the medium, which has been proven to inhibit yeast cell growth. Decane had a

444 good biocompatibility with the strain used. Moreover, it has a good affinity with IAA

445 which is very volatile and poorly soluble in water, so it decreased the loss of IAA by

446 stripping. In addition, thanks to the model it is easier to monitor IAA production from

447 a single measurement in the decane phase and to calculate the total amount produced.

448 The model describes not only the biological production of IAA, but also includes the

449 physical distribution of the ester according to key factors, like aeration, medium

450 composition changes through fermentation and volume ratio of both liquid phases. It

451 provides a more complete panorama of the process, allowing to test different

452 configurations and find the best compromise between fermentation conditions and

453 IAA retention to get the highest possible amount of product at acceptable purification

454 costs.

455 Further investigation is needed in order to better understand the whole process. For

456 example, aeration is a very important factor for IAA production, but it also increases 
457 the loss by stripping, so it is a key process factor that has to be controlled. The 458 developed model is able to determine the rate of isoamyl acetate loss due to aeration, 459 and it could be further extended to include the effect of different air flow rates on 460 IAA production and thus indicate the best compromise. After testing model 461 predictions in a wide range of situations of practical interest, its implementation in 462 industrial processes could make it a valuable tool for process optimization and 463 provide a solid basis for choosing and developing a suitable product recovery 464 strategy. 


\begin{tabular}{|c|c|c|}
\hline \multicolumn{2}{|c|}{ Nomenclature } & \multirow{2}{*}{$\begin{array}{l}\text { Units } \\
\mathrm{cm}^{2}\end{array}$} \\
\hline$A$ & Gas-liquid contact area & \\
\hline C & Isoamyl acetate concentration & $\mathrm{g} \mathrm{L}^{-1}$ \\
\hline$D_{g}$ & Specific aeration rate of the medium & $h^{-1}$ \\
\hline EtOH & Ethanol concentration & $\mathrm{g} \mathrm{L}^{-1}$ \\
\hline$I A O H$ & Isoamyl alcohol concentration & $\mathrm{g} \mathrm{L}^{-1}$ \\
\hline$K_{d q}$ & Liquid-liquid partition coefficient & $\mathrm{g} \mathrm{g}^{-1}$ \\
\hline$K_{g q}$ & Gas-liquid partition coefficient & $\mathrm{g} \mathrm{g}^{-1}$ \\
\hline$K_{I A O H}$ & $\begin{array}{l}\text { Isoamyl alcohol saturation coefficient for isoamyl acetate } \\
\text { production }\end{array}$ & $\mathrm{g} \mathrm{L}^{-1}$ \\
\hline$K_{L}$ & L-Leucine saturation coefficient for isoamyl alcohol production & $\mathrm{g} \mathrm{L}^{-1}$ \\
\hline$K_{S}$ & Sugar saturation coefficient for biomass production & $\mathrm{g} \mathrm{L}^{-1}$ \\
\hline$K_{S I A}$ & Sugar saturation coefficient for isoamyl alcohol production & $\mathrm{g} \mathrm{L}^{-1}$ \\
\hline$k_{d}$ & $\begin{array}{l}\text { Overall mass transfer coefficient of isoamyl acetate between } \\
\text { the decane and gas phase }\end{array}$ & $\mathrm{cm} \mathrm{h}^{-1}$ \\
\hline$k_{q}$ & $\begin{array}{l}\text { Overall mass transfer coefficient of isoamyl acetate between } \\
\text { the aqueous and gas phase }\end{array}$ & $\mathrm{cm} \mathrm{h}^{-1}$ \\
\hline$k_{l} a_{l}$ & Volumetric mass transfer coefficient between both liquid & $\mathrm{h}^{-1}$ \\
\hline
\end{tabular}




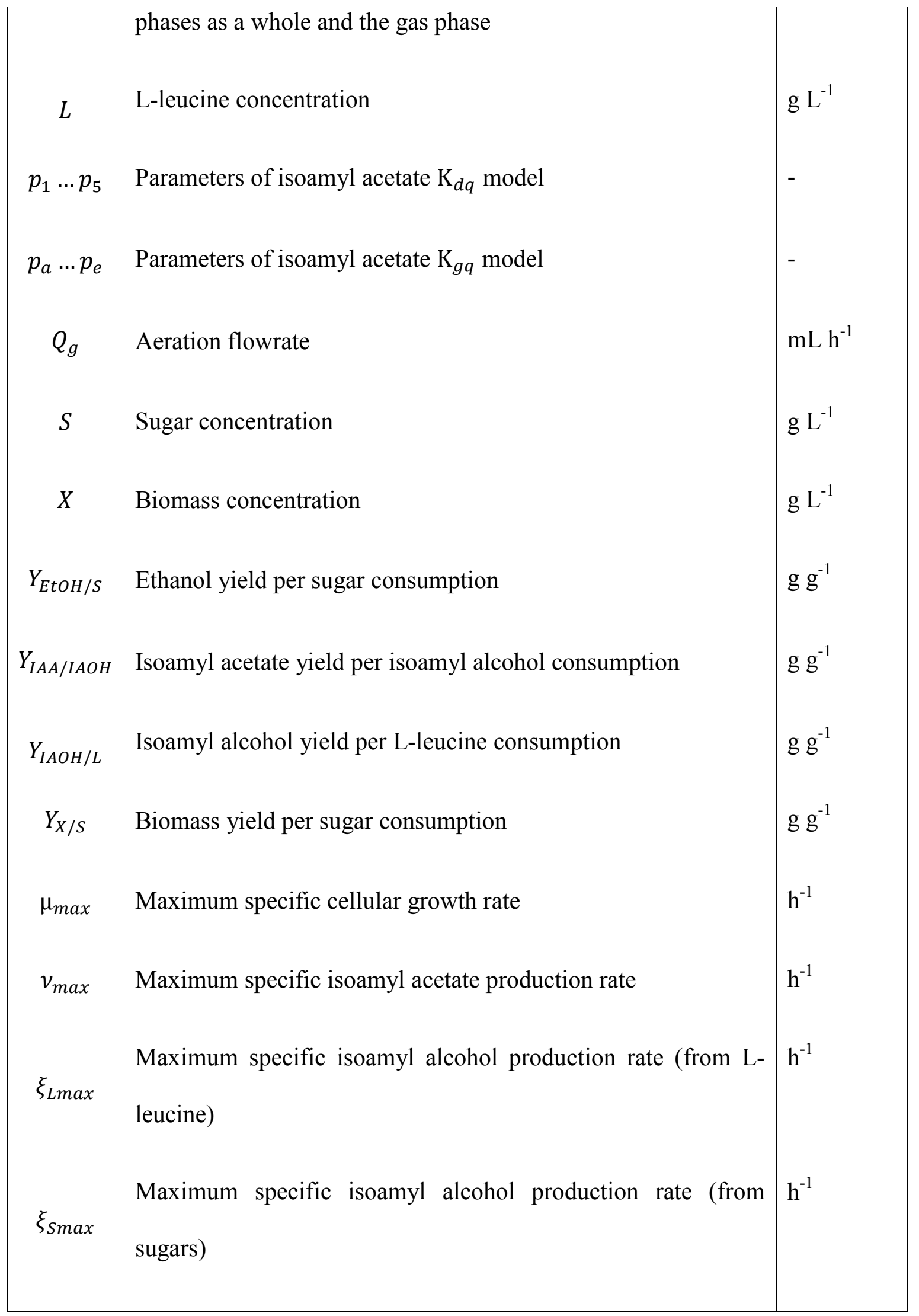




\begin{tabular}{|ll|}
\hline Subscripts & \\
$\mathrm{d}$ & Decane phase \\
$\mathrm{q}$ & Gas phase \\
$\mathrm{f}$ & Aqueous phase \\
$\mathrm{t}$ & Total \\
0 & Initial value \\
$*$ & Value at equilibrium \\
\hline Abbreviations \\
\hline
\end{tabular}

466

467

468 


\section{REFERENCES}

470 [1] S. Torres, M.D. Baigorí, S.L. Swathy, A. Pandey, G.R. Castro, Enzymatic

471 synthesis of banana flavour (isoamyl acetate) by Bacillus licheniformis S-86 esterase, 472 Food Res. Int. 42 (2009) 454-460.

473 [2] W. Osorio-Viana, H.N. Ibarra-Taquez, I. Dobrosz-Gómez, M.Á. Gómez474 García, Hybrid membrane and conventional processes comparisonfor isoamyl acetate 475 production, Chem. Eng. Process. 76 (2014) 70-82.

476 [3] N. Mhetras, S. Patil, D. Gokhale, Lipase of Aspergillus niger NCIM 1207: A 477 Potential Biocatalyst for Synthesis of Isoamyl Acetate, Indian J Microbiol. 50 (2010) $478 \quad 432-437$.

479 [4] M. Asunción, M. Sanromán, Production of Food Aroma Compounds: 480 Microbial and Enzymatic Methodologies, Food Technol Biotechnol. (2006) 335-353.

481 [5] N. Ben Akacha, M. Gargouri, Microbial and enzymatic technologies used for 482 the production of natural aroma compounds: Synthesis, recovery modeling, and 483 bioprocesses, Food Bioprod. Process. $94 \quad$ (2015) 675-706. 484 doi:10.1016/j.fbp.2014.09.011.

485 [6] M. Yilmaztekin, H. Erten, T. Cabaroglu, Enhanced production of isoamyl 486 acetate from beet molasses with addition of fusel oil by Williopsis saturnus var. 487 saturnus, Food Chem. 112 (2009) 290-294.

488 [7] U. Krings, R.G. Berger, Biotechnological production of flavours and 489 fragrances, Appl Microbiol Biotechnol. 49 (1998) 1-8. 
490 [8] J. Schrader, M.M.W. Etschmann, D. Sell, J.-M. Hilmer, J. Rabenhorst, 491 Applied biocatalysis for the synthesis of natural flavour compounds - current 492 industrial processes and future prospects, Biotechnol. Lett. 26 (2004) 463-472. 493 doi:10.1023/B:BILE.0000019576.80594.0e.

494 [9] M. Cvjetko, J. Vorkapić-Furač, P. Žnidaršič-Plazl, Isoamyl acetate synthesis 495 in imidazolium-based ionic liquids using packed bed enzyme microreactor, Process 496 Biochem. 47 (2012) 1344-1350. doi:10.1016/j.procbio.2012.04.028.

497 [10] M.J. Eisenmenger, J.I. Reyes-De-Corcuera, Enhanced synthesis of isoamyl 498 acetate using an ionic liquid-alcohol biphasic system at high hydrostatic pressure, J. 499 Mol. Catal. B Enzym. 67 (2010) 36-40. doi:10.1016/j.molcatb.2010.07.002.

500 [11] E. Fehér, V. Illeová, I. Kelemen-Horváth, K. Bélafi-Bakó, M. Polakovič, L. 501 Gubicza, Enzymatic production of isoamyl acetate in an ionic liquid-alcohol biphasic 502 system, J. Mol. Catal. B $\quad$ Enzym. $50 \quad$ (2008) 28-32. 503 doi:10.1016/j.molcatb.2007.09.019.

504 [12] S.H. Krishna, S. Divakar, S.. Prapulla, N.. Karanth, Enzymatic synthesis of 505 isoamyl acetate using immobilized lipase from Rhizomucor miehei, J. Biotechnol. 87 506 (2001) 193-201. doi:10.1016/S0168-1656(00)00432-6.

507 [13] M.D. Romero, L. Calvo, C. Alba, A. Daneshfar, H.S. Ghaziaskar, Enzymatic 508 synthesis of isoamyl acetate with immobilized Candida antarctica lipase in n-hexane, 509 Enzyme Microb. Technol. 37 (2005) 42-48. doi:10.1016/j.enzmictec.2004.12.033. 
510 [14] M.D. Romero, L. Calvo, C. Alba, M. Habulin, M. Primožič, ž. Knez,

511 Enzymatic synthesis of isoamyl acetate with immobilized Candida antarctica lipase

512 in supercritical carbon dioxide, J. Supercrit. Fluids. 33 (2005) 77-84.

513 doi:10.1016/j.supflu.2004.05.004.

514 [15] P. Žnidaršič-Plazl, I. Plazl, Modelling and experimental studies on lipase515 catalyzed isoamyl acetate synthesis in a microreactor, Process Biochem. 44 (2009) 516 1115-1121. doi:10.1016/j.procbio.2009.06.003.

517 [16] T. Asano, T. Inoue, N. Kurose, N. Hiraoka, S. Kawakita, Improvement of 518 Isoamyl Acetate Productivity in Sake Yeast by Isolating Mutants Resistant to 519 Econazole, J. Biosci. Bioeng. 87 (1999) 697-699.

520 [17] K. Hirooka, Y. Yamamoto, N. Tsutsui, T. Tanaka, Improved production of 521 isoamyl acetate by a sake yeast mutant resistant to an isoprenoid analog and its 522 dependence on alcohol acetyltransferase activity, but not on isoamyl alcohol 523 production, J. Biosci. Bioeng. 99 (2005) 125-129. doi:10.1263/jbb.99.125.

524 [18] C. Plata, J.C. Mauricio, C. Millán, J.M. Ortega, Influence of glucose and 525 oxygen on the production of ethyl acetate and isoamyl acetate by a Saccharomyces 526 cerevisiae strain during alcoholic fermentation, World J. Microbiol. Biotechnol. 00 527 (2004) 1-7.

528 [19] M.G. Quilter, J.C. Hurley, F.J. Lynch, M.G. Murphy, The production of 529 isoamyl acetate from amyl alcohol by Saccharomyces cerevisiae, J. Inst. Brew. 109 $530 \quad$ (2003) 34-40. 
531 [20] V. Rojas, J.V. Gil, F. Piñaga, P. Manzanares, Studies on acetate ester 532 production by non-Saccharomyces wine yeasts, Int. J. Food Microbiol. 70 (2001) $533 \quad 283-289$.

534 [21] T. Lamer, H.E. Spinnler, I. Souchon, A. Voilley, Extraction of benzaldehyde 535 from fermentation broth by pervaporation, Process Biochem. 31 (1996) 533-542. 536 doi:10.1016/0032-9592(95)00098-4.

537 [22] A. Freeman, J.M. Woodley, M.D. Lilly, In Situ Product Removal as a Tool for 538 Bioprocessing, Nat Biotech. 11 (1993) 1007-1012. doi:10.1038/nbt0993-1007.

539 [23] S.H. Krishnaa, B. Manoharb, S. Divakara, S.G. Prapullaa, N.G. Karanth, 540 Optimization of isoamyl acetate production by using immobilized lipase from Mucor 541 miehei by response surface methodology, Enzyme Microb. Technol. 26 (2000) 131542136.

543 [24] G. Hernández-Carbajal, O.M. Rutiaga-Quiñones, A. Pérez-Silva, G. Saucedo544 Castañeda, A. Medeiros, C.R. Soccol, N.Ó. Soto-Cruz, Screening of native yeast 545 from Agave duranguensis fermentation for isoamyl acetate production, Braz. Arch. 546 Biol. Technol. 56 (2013) 357-363. doi:10.1590/S1516-89132013000300002.

547 [25] G.L. Miller, R. Blum, W.E. Glennon, A.L. Burton, Measurement of 548 carboxymethylcellulase activity, Anal. Biochem. 1 (1960) 127-132.

549 [26] S. Yokoyama, J.-I. Hiramatsu, A Modified Ninhydrin Reagent Using Ascorbic 550 Acid Instead of Potassium Cyanide, J. Biosci. Bioeng. 95 (2003) 204-205.

551 [27] Agilent Technologies, Agilent J\&W. GC Column Selection Guide, (2007). 
552 [28] S. Morakul, V. Athes, J.-R. Mouret, J.-M. Sablayrolles, Comprehensive Study 553 of the Evolution of Gas-Liquid Partitioning of Aroma Compounds during Wine 554 Alcoholic Fermentation, J. Agric. Food Chem. 58 (2010) 10219-10225.

555 [29] L. Ettre, C. Welter, B. Kolb, Determination of gas-liquid partition coefficients 556 by automatic equilibrium headspace-gas chromatography utilizing the phase ratio 557 variation method, Chromatographia. (1993) 73-84.

558 [30] J.R. Mouret, V. Farines, J.M. Sablayrolles, I.C. Trelea, Prediction of the 559 production kinetics of the main fermentative aromas in winemaking fermentations, 560 Biochem. Eng. J. 103 (2015) 211-218. doi:10.1016/j.bej.2015.07.017.

561 [31] M. Marin, I. Baek, A.J. Taylor, Volatile Release from Aqueous Solutions 562 under Dynamic Headspace Dilution Conditions, J. Agric. Food Chem. 47 (1999) $5634750-4755$.

564 [32] A. Piendl, E. Geiger, Technological factors in the formation of esters during 565 fermentation, Brew. Dig. 55 (1980) 26-35.

566 [33] S. Derrick, P.J. Large, Activities of the enzimes of the Ehrlich pathway and 567 formation of branched-chain alcohols in Saccharomyces cerevisiae and Candida 568 utilis grown in continous cuture on valine or amonium as sole nitrogen source, J. 569 Gen. Microbiol. 139 (1993) 2783-2792.

570 [34] S. Morakul, J.-R. Mouret, P. Nicolle, I.C. Trelea, J.-M. Sablayrolles, V. Athes, 571 Modelling of the gas-liquid partitioning of aroma compounds during wine alcoholic 
572 fermentation and prediction of aroma losses, Process Biochem. 46 (2011) 1125-1131.

573 doi:10.1016/j.procbio.2011.01.034.

574 [35] Y. Inoue, S. Trevanichi, K. Fukuda, S. Izawa, Y. Wakai, A. Kimura, Roles of 575 Esterase and Alcohol Acetyltransferase on Production of Isoamyl Acetate in 576 Hansenula mrakii, J. Agric. Food Chem. 45 (1997) 644-649. doi:10.1021/jf960648o.

577 [36] A. Dourado, G. Goma, U. Albuquerque, Y. Sevely, Modeling and static 578 optimization of the ethanol production in a cascade reactor. I. Modeling, Biotechnol. 579 Bioeng. 29 (1987) 187-194. doi:10.1002/bit.260290208.

580 [37] G.H.S.F. Ponce, J. Moreira Neto, S.S. De Jesus, J.C. de C. Miranda, R. Maciel 581 Filho, R.R. de Andrade, M.R. Wolf Maciel, Sugarcane molasses fermentation with in 582 situ gas stripping using low and moderate sugar concentrations for ethanol 583 production: Experimental data and modeling, Biochem. Eng. J. 110 (2016) 152-161. 584 doi:10.1016/j.bej.2016.02.007.

585 [38] D. Das, D. Charumathi, N. Das, Combined effects of sugarcane bagasse 586 extract and synthetic dyes on the growth and bioaccumulation properties of Pichia 587 fermentans MTCC 189, J. Hazard. Mater. 183 (2010) 497-505. 588 doi:10.1016/j.jhazmat.2010.07.051.

589 [39] C. Martinez-Anaya, In yeast, the pseudohyphal phenotype induced by isoamyl 590 alcohol results from the operation of the morphogenesis checkpoint, J. Cell Sci. 116 591 (2003) 3423-3431. doi:10.1242/jcs.00634. 
592 [40] K. Kern, C. Nunn, A. Pichova, J. Dickinson, Isoamyl alcohol-induced 593 morphological change in involves increases in mitochondria and cell wall chitin 594 content, FEMS Yeast Res. 5 (2004) 43-49. doi:10.1016/j.femsyr.2004.06.011.

595 [41] M.G. Quilter, J.C. Hurley, F.J. Lynch, M.G. Murphy, The production of 596 isoamyl acetate from amyl alcohol by Saccharomyces cerevisiae, J. Inst. Brew. 109 $597 \quad$ (2003) 34-40.

598 


\section{$599 \quad$ Figure legends}

600 Figure 1. Schematic representation of the metabolic pathways involved in isoamyl 601 acetate synthesis [32].

602 Figure 2. Gas-aqueous phase partition coefficient $\left(K_{g q}\right)$ values of isoamyl acetate for 603 different fermentation medium compositions. Error bars represent standard deviation $604(\mathrm{n}=2)$, different letters correspond to significantly different values.

605 Figure 3. Decane-aqueous phase partition coefficient $\left(K_{d q}\right)$ values of isoamyl acetate 606 for different fermentation medium compositions. Error bars represent standard 607 deviation $(\mathrm{n}=2)$, different letters correspond to significantly different values.

608 Figure 4. Isoamyl acetate stripping due to air flow. Symbols correspond to 609 experimental measurements and error bars represent standard error $(n=2)$. Solid 610 lines represent model predictions considering gas-liquid mass transfer resistance; 611 dashed lines represent model predictions assuming gas and liquid phases in 612 equilibrium.

613 Figure 5. Comparison between model predictions and measured data in the validation

614 experiment, with L-leucine addition at 12 hours of fermentation. Symbols: 615 experimental measurements, solid lines: model predictions, dotted line: produced 616 isoamyl acetate without considering losses by air stripping.

617 Figure 6. Final isoamyl acetate concentration in decane at different concentrations of 618 L-leucine. 
619 Figure 7.a) Isoamyl acetate distribution in the fermentation-extraction system and 620 losses by stripping for different decane/medium ratios, b) Isoamyl acetate recovery 621 and final concentration in decane at different decane/medium ratios. Results obtained 622 from model simulations. 


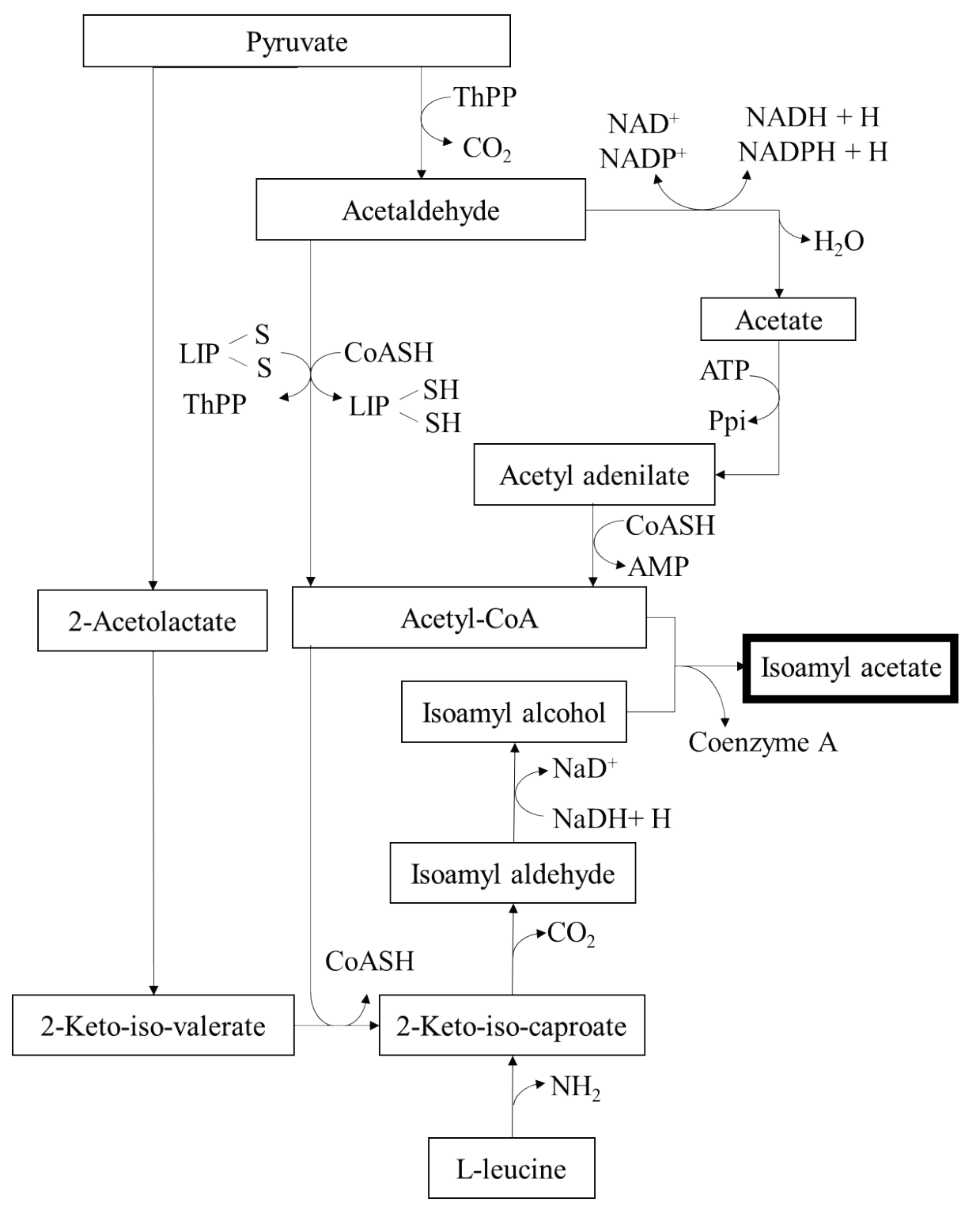

624 Figure 1. Schematic representation of the metabolic pathways involved in isoamyl acetate synthesis [32]. 


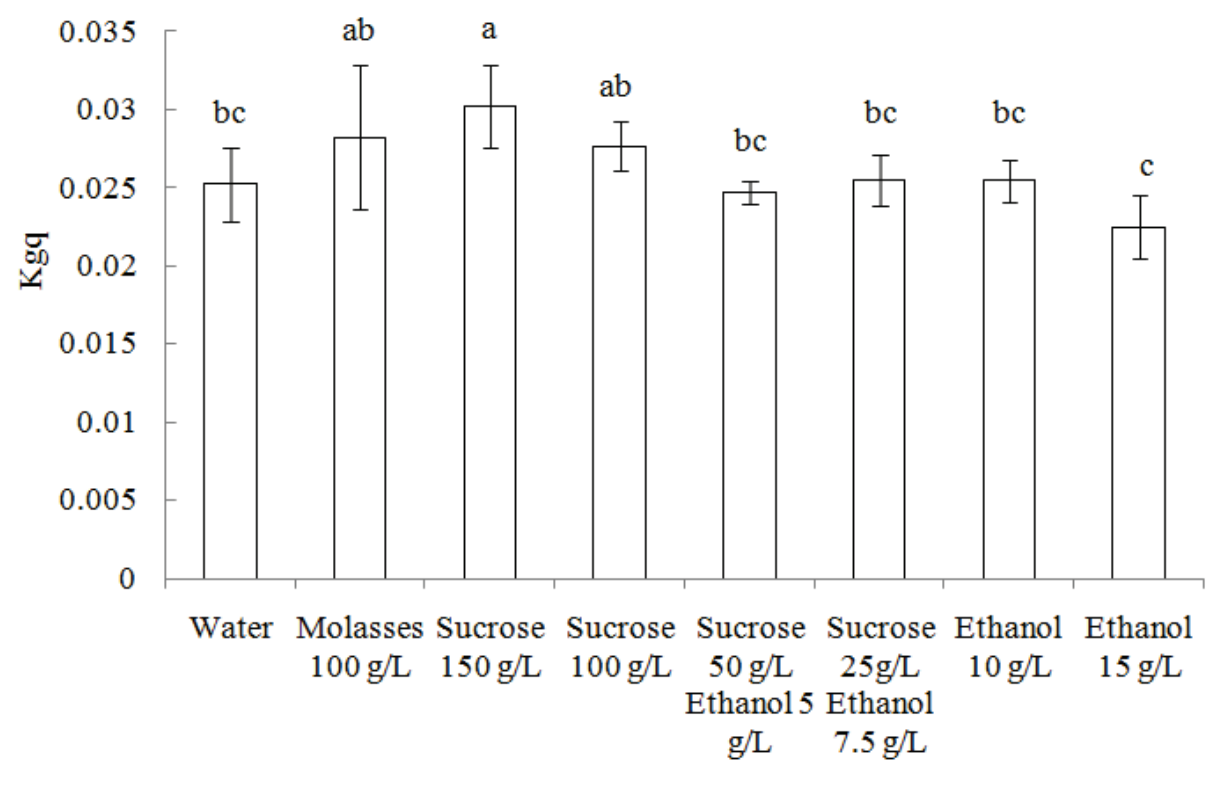

627 Figure 2. Gas-aqueous phase partition coefficient $\left(K_{g q}\right)$ values of isoamyl acetate for 628 different fermentation medium compositions. Error bars represent standard deviation $629 \quad(\mathrm{n}=2)$, different letters correspond to significantly different values.

630 


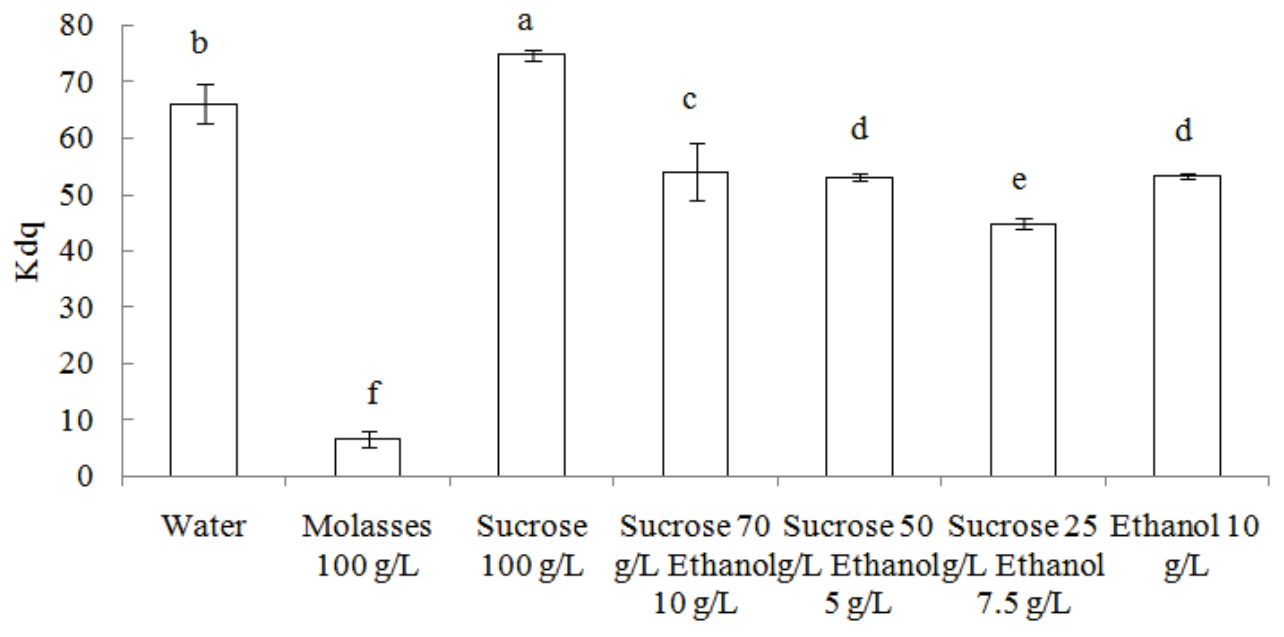

632 Figure 3. Decane-aqueous phase partition coefficient $\left(K_{d q}\right)$ values of isoamyl acetate

633 for different fermentation medium compositions. Error bars represent standard

634 deviation $(\mathrm{n}=2)$, different letters correspond to significantly different values.

635 


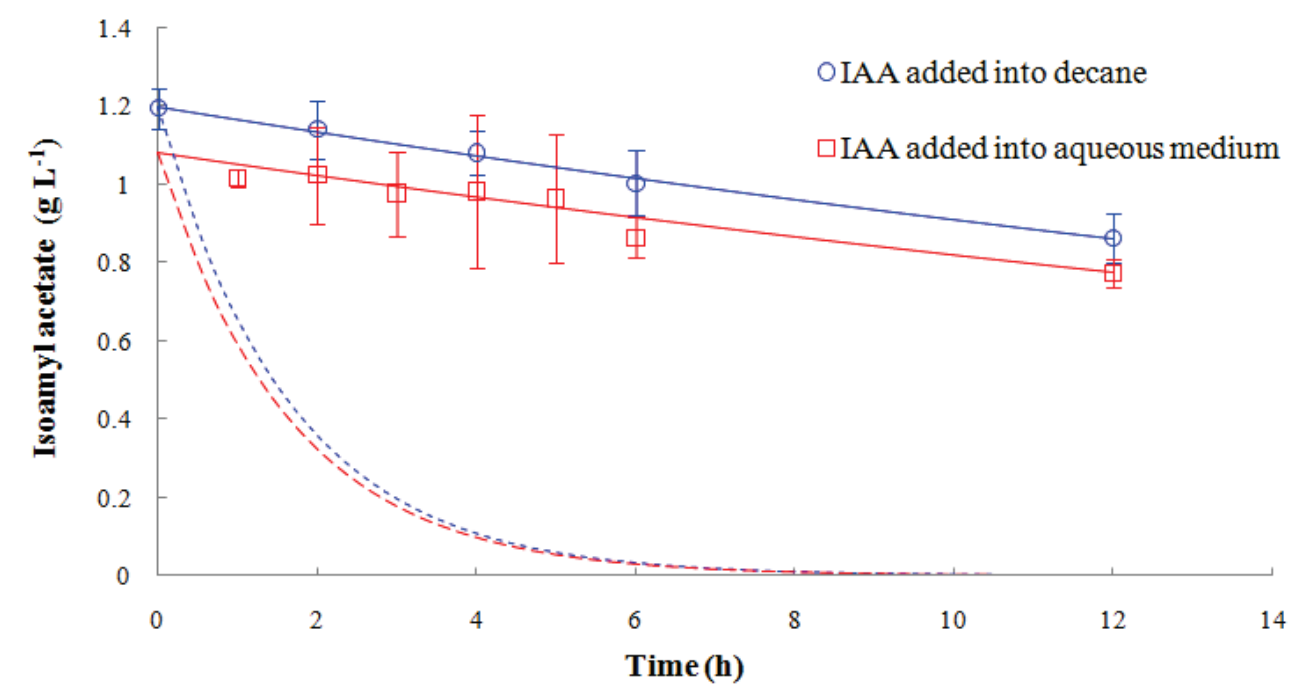

637

Figure 4. Isoamyl acetate stripping due to air flow. Symbols correspond to

638 experimental measurements and error bars represent standard error $(n=2)$. Solid lines

639 represent model predictions considering gas-liquid mass transfer resistance; dashed

640 lines represent model predictions assuming gas and liquid phases in equilibrium.

641 

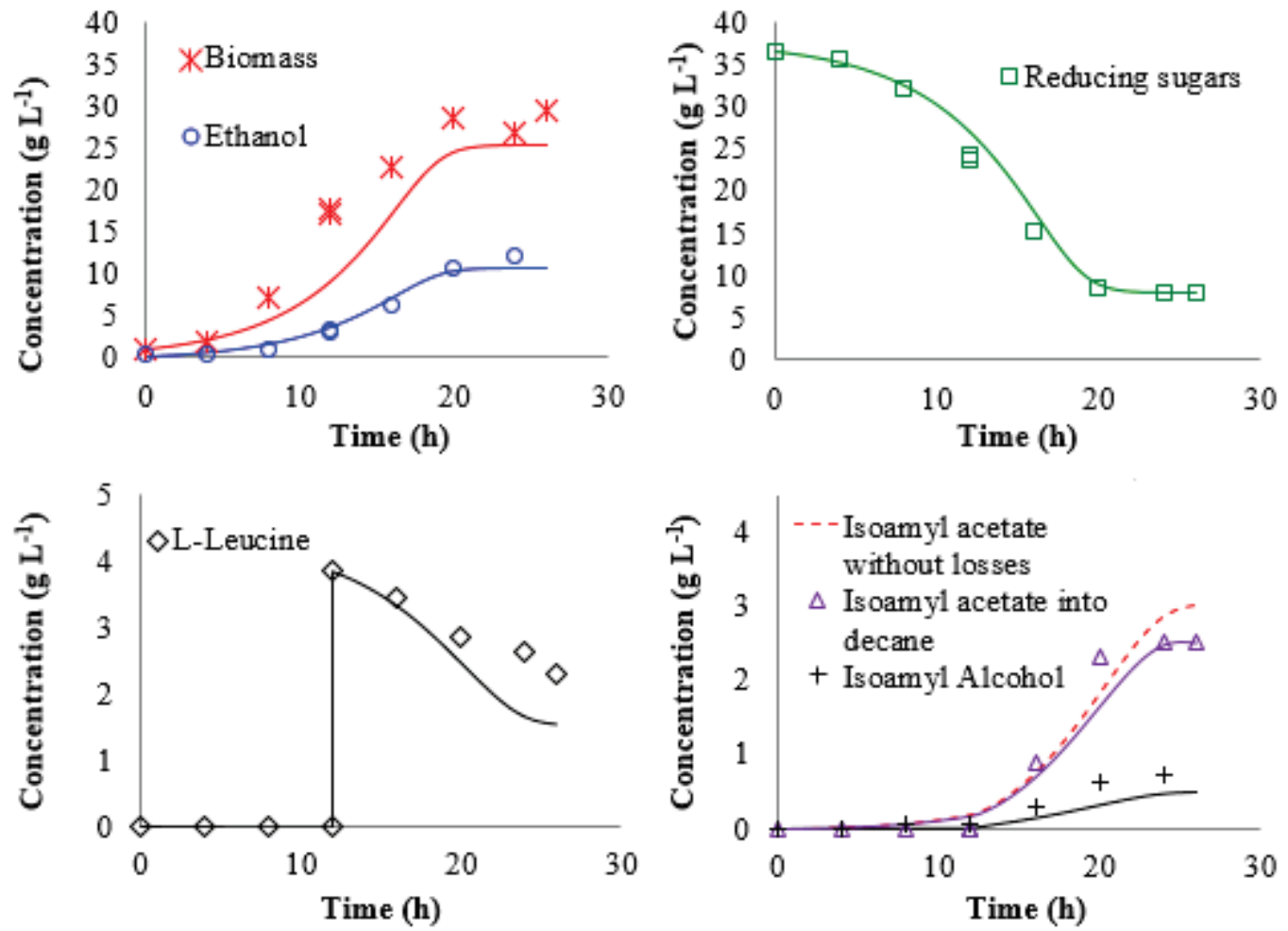

644 Figure 5. Comparison between model predictions and measured data in the validation

645 experiment, with L-leucine addition at 12 hours of fermentation. Symbols:

646 experimental measurements, solid lines: model predictions, dotted line: produced

647 isoamyl acetate without considering losses by air stripping. 


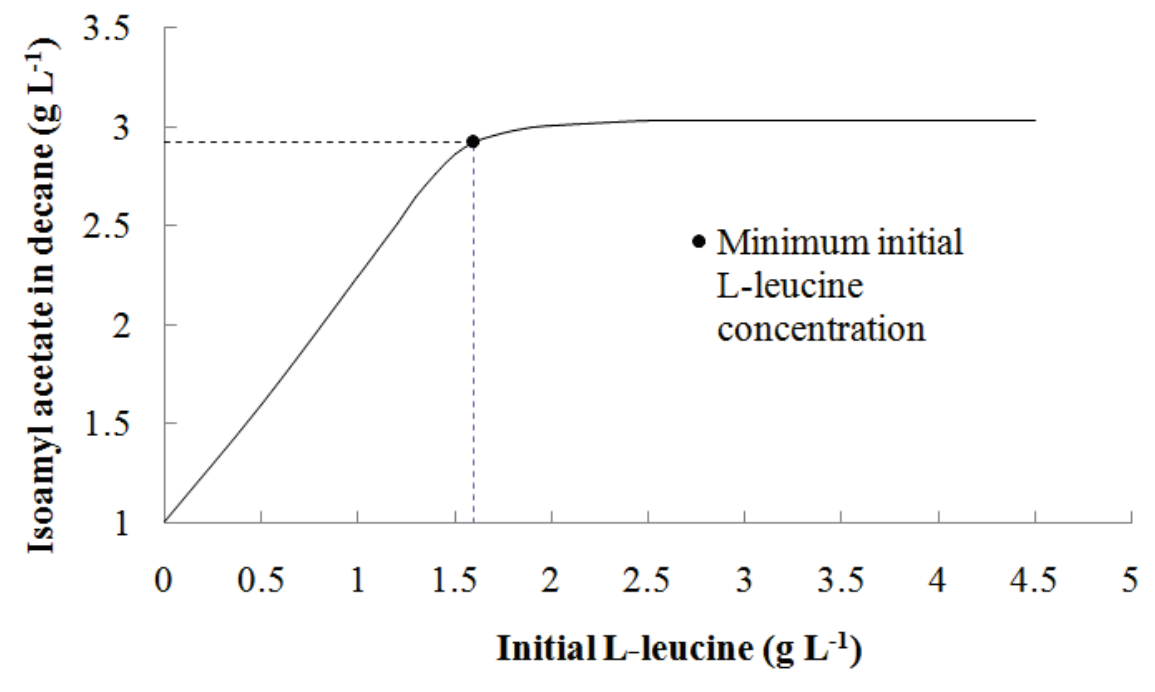

650 Figure 6. Final isoamyl acetate concentration in decane predicted by the model for 651 different initial concentrations of L-leucine. 

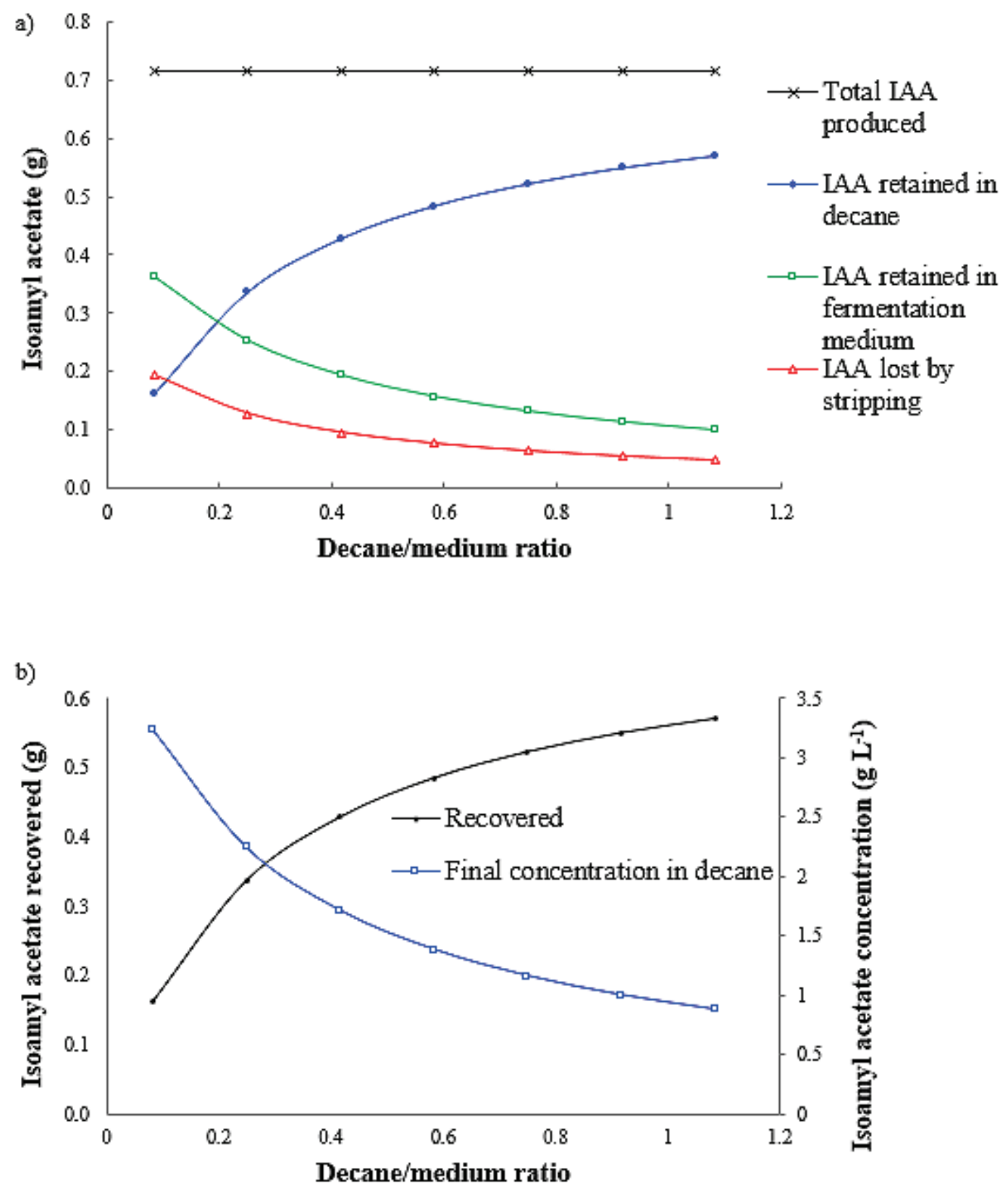

652

653 Figure 7. a) Isoamyl acetate distribution in the fermentation-extraction system and 654 losses by stripping for different decane/medium ratios, b) Isoamyl acetate recovery 655 and final concentration in decane at different decane/medium ratios. Results obtained 656 from model simulations. 
Table 1. Mass balance and kinetic equations for the fermentation model, without considering isoamyl acetate extraction by decane and losses by stripping

\begin{tabular}{|c|c|c|}
\hline Compounds & Equations & \\
\hline Biomass & $\frac{d X}{d t}=\mu X$ & (14) \\
\hline Ethanol & $\frac{d E t O H}{d t}=\frac{Y_{E t O H / S}}{Y_{X / S}} \mu X$ & $(15)$ \\
\hline Isoamyl alcohol & $\frac{d I A O H}{d t}=\xi_{S} X+\xi_{L} X-\frac{1}{Y_{I A A / I A O H}} v X$ & (16) \\
\hline Isoamyl acetate & $\frac{d C}{d t}=v X$ & (17) \\
\hline Fermentable reducing sugars & $\frac{d S_{f}}{d t}=-\frac{1}{Y_{X / S}} \mu X$ & (18) \\
\hline Leucine & $\frac{d L}{d t}=-\frac{1}{Y_{I A O H / L}} \xi_{L} X$ & (19) \\
\hline Kinetic parameters & Equations & \\
\hline Specific growth rate & $\mu=\mu_{\max } \frac{S_{f}}{K_{S}+S_{f}}$ & $(20)$ \\
\hline $\begin{array}{l}\text { Specific isoamyl alcohol } \\
\text { production rate (with sugar } \\
\text { consumption) }\end{array}$ & $\xi_{S}=\xi_{S \max } \frac{S_{f}}{K_{S I A}+S_{f}}$ & $(21)$ \\
\hline $\begin{array}{l}\text { Specific isoamyl alcohol } \\
\text { production rate (with L-leucine }\end{array}$ & $\xi_{L}=\xi_{\text {Lmax }} \frac{L}{K_{L}+L} \frac{S_{f}}{K_{S I A}+S_{f}}$ & $(22)$ \\
\hline consumption) & & \\
\hline $\begin{array}{c}\text { Specific isoamyl acetate } \\
\text { production rate }\end{array}$ & $v=v_{\max } \frac{I A O H}{K_{I A O H}+I A O H} \frac{S_{f}}{K_{S I A}+S_{f}}$ & $(23)$ \\
\hline
\end{tabular}


Table 2. Parameter values for isoamyl acetate partition coefficient in the fermentation system.

\begin{tabular}{|c|c|c|c|}
\hline Partition coefficient & Parameter & Factor & Value \pm standard error \\
\hline \multirow{5}{*}{ Gas-liquid } & $p_{1}$ & - & $-3.716 \pm 0.026$ \\
\hline & $p_{2}$ & $S_{t}$ & $0.0014 \pm 0.0004$ \\
\hline & $p_{3}$ & $E$ & 0 \\
\hline & $p_{4}$ & $S_{t} E$ & 0 \\
\hline & $p_{5}$ & $M$ & 0 \\
\hline \multirow{5}{*}{ Liquid-liquid } & $p_{a}$ & - & $4.211 \pm 0.083$ \\
\hline & $p_{b}$ & $S_{t}$ & 0 \\
\hline & $p_{c}$ & $E$ & $-0.031 \pm 0.012$ \\
\hline & $p_{d}$ & $S_{t} E$ & 0 \\
\hline & $p_{e}$ & $M$ & $-2.326 \pm 0.145$ \\
\hline
\end{tabular}

660

661 
Table 3. Model parameters and experimental initial conditions

\begin{tabular}{|c|c|c|c|c|}
\hline Parameters & & Value \pm standard error & & Unit \\
\hline$\mu_{\max }$ & & $0.230 \pm 0.006$ & & $\mathrm{~h}^{-1}$ \\
\hline$\xi_{\text {Smax }}$ & & $0.0013 \pm 0.0003$ & & $\mathrm{~h}^{-1}$ \\
\hline$\xi_{\text {Lmax }}$ & & $0.0046 \pm 0.0005$ & & $\mathrm{~h}^{-1}$ \\
\hline$v_{\max }$ & & $0.0062 \pm 0.0004$ & & $\mathrm{~h}^{-1}$ \\
\hline$Y_{X / S}$ & & $0.854 \pm 0.050$ & & $\mathrm{~g} \mathrm{~g}^{-1}$ \\
\hline$Y_{E t O H / S}$ & & $0.373 \pm 0.020$ & & $\mathrm{~g} \mathrm{~g}^{-1}$ \\
\hline$Y_{I A O H / L}$ & & $0.452 \pm 0.055$ & & $\mathrm{~g} \mathrm{~g}^{-1}$ \\
\hline$Y_{I A A / I A O H}$ & & $130 / 88$ & & $\mathrm{~g} \mathrm{~g}^{-1}$ \\
\hline$K_{S}$ & & $6.41 \pm 0.57$ & & $\mathrm{~g} \mathrm{~L}^{-1}$ \\
\hline$K_{S I A}$ & & 0.02 & & $\mathrm{~g} \mathrm{~L}^{-1}$ \\
\hline$K_{L}$ & & 0.02 & & $\mathrm{~g} \mathrm{~L}^{-1}$ \\
\hline$K_{I A O H}$ & & 0.02 & & $\mathrm{~g} \mathrm{~L}^{-1}$ \\
\hline$k_{l} a_{l}$ & & $0.0117 \pm 0.0003$ & & $\mathrm{~h}^{-1}$ \\
\hline Initial conditions & 1) No addition & 2) Addition at $t_{0}$ & 3) Addition at $t_{12}$ & \\
\hline$X_{0}$ & $0.86 \pm 0.12$ & $0.89 \pm 0.04$ & $1.01 \pm 0.01$ & $\mathrm{~g} \mathrm{~L}^{-1}$ \\
\hline$S_{0}$ & $35.18 \pm 0.53$ & $32.24 \pm 1.88$ & $36.40 \pm 1.03$ & $\mathrm{~g} \mathrm{~L}^{-1}$ \\
\hline$L_{0}$ & 0.0093 & $4.03 \pm 0.02$ & 0.0093 & $\mathrm{~g} \mathrm{~L}^{-1}$ \\
\hline $\mathrm{EtOH}_{0}$ & $0.21 \pm 0.03$ & $0.17 \pm 0.02$ & $0.23 \pm 0.05$ & $\mathrm{~g} \mathrm{~L}^{-1}$ \\
\hline$I A O H_{0}$ & 0 & 0 & 0 & $\mathrm{~g} \mathrm{~L}^{-1}$ \\
\hline$C_{d 0}$ & 0 & 0 & 0 & $\mathrm{~g} \mathrm{~L}^{-1}$ \\
\hline
\end{tabular}

662 